\title{
El Secreto de Andrómaca: La esclavitud de las labores domésticas en La Condición Humana de Hannah Arendt
}

\section{The Secret of Andromaca: the Slavery of Housework in Hannah Arendt's The Human Condition}

RECIBIDO: 22 DE NOVIEMBRE DE 2019/ACEPTADO: 28 DE FEBRERO DE 2020

\section{FERNANDO GALINDO}

Facultad de Economía

Universidad Anáhuac (México)

fernando.galindocr@anahuac.mx

\section{RAFAEL HURTADO}

Departamento de Humanidades

Universidad Panamericana (México)

rhurtado@up.edu.mx
Resumen: La nota distintiva más noble del pensamiento de Hannah Arendt es su inequívoca apuesta por la libertad. Su amor por este concepto la llevó a considerar las labores domésticas como actividades que limitan el desarrollo humano político. El texto analiza el concepto de labor y lo vincula con la noción de necesidad en el griego clásico. En esa línea, se ofrece una apología del concepto de "labor", desde de una interpretación relativa a un pasaje clave de la Iliada, citado por Arendt misma para criticar la necesidad, un pasaje que interpretado desde nuestra óptica nos parece que permite una mejor comprensión de la labor, las labores domésticas y la relevancia del hogar.

Palabras clave: Hannah Arendt, La Condición Humana, Labor, Trabajo, Trabajo Doméstico.
Abstract: The following text analyses Arendt's peculiar concept of "labor" as it appears in her famous essay The Human Condition. It searches for the roots of this concept in the ancient Greek world for "necessity". It explains how the different meanings of necessity translate into the peculiar notion hold by Arendt, and how these meanings defined her conception of domestic work. It also offers a brief apology of domestic work in accordance with a key passage in the lliad that is quoted by Arendt. The text interprets this passage in its original context and shows how a quite different comprehension of domestic work emerges.

Keywords: Hannah Arendt, The Human Condition, Labor, Work, Domestic Work, Home. 


\section{INTRODUCCIÓN: DIÁLOGO ENTRE NECESIDAD Y LIBERTAD}

Hannah Arendt es una de las pensadoras más originales y relevantes del siglo XX. Su cosmología política orbita en torno al concepto de libertad. Para Arendt el sentido último de la política es la libertad. En la tradición de Montesquieu y de Alexis de Tocqueville, Arendt busca definir las circunstancias, requerimientos y condiciones generales que permiten el florecimiento de a libertad. Arendt opta por una libertad humana original y fundamental, en la medida en que cada ser humano representa por el simple hecho de su nacimiento un nuevo y radical inicio. Considera, sin embargo, que esta libertad fundamental sólo se realiza plenamente si la persona es capaz de participar de manera libre y singular en la definición de las condiciones y la organización de la vida en común: Es sólo en el ámbito político donde la "esencia" personal logra proyectarse plenamente. El máximo grado de libertad humana y desarrollo humano es entonces la libertad política.

Arendt no guarda falsas ilusiones respecto a las posibilidades de realizar la libertad humana plenamente en la sociedad moderna. Un obstáculo obvio en su tiempo era la presencia del totalitarismo soviético, pero ella denuncia igualmente a la sociedad de consumo, propia de las sociedades libres, como un impedimento para la libertad política. Más allá de estas obvias amenazas, subyace una oposición enraizada en la condición humana: la oposición entre necesidad y libertad.

En opinión de Arendt la libertad política (la plena libertad humana), sólo se ha realizado por instantes en distintos momentos históricos. Uno de esos momentos es la esfera política constituida por los ciudadanos de la Atenas clásica en esa peculiar institución política que conocemos como polis. Gracias a la tajante separación del ámbito privado, confinado a la unidad doméstica (oĩ̌kos), y el ámbito público, establecido en el espacio simbólico y real del ágora (ảyopó), los griegos lograron limitar el impacto de la necesidad en las relaciones humanas y así construir para unos pocos un espacio de libertad.

En ese sentido, la oposición fundamental entre necesidad y libertad está presente en la distinción que hace Arendt de las tres actividades humanas fundamentales: labor, trabajo y acción; así como en los "escenarios" (en el vocabulario de Arendt) al que cada una de estas actividades da lugar. Como mostraremos, la noción de necesidad de Arendt es una apropiación y reinterpretación del término griego àvó $\gamma \kappa \eta$, que en griego clásico significa necesidad, pero también violencia y compulsión.

La oposición entre necesidad y libertad se proyecta en una oposición funda-

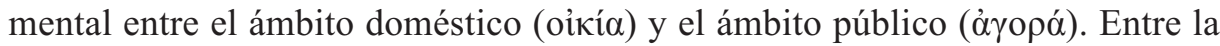


"oscuridad" de lo doméstico y la "luz pública" de la política. A diferencia de

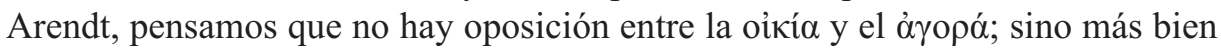
una relación simbiótica, no de exclusión. Pensamos además que hay elementos en el mundo clásico que hablan a favor de esta relación, como intentaremos mostrar en este artículo de la mano de una cita de la Ilíada que juega un papel medular en la argumentación de Arendt. Antes de analizar este importante fragmento es conveniente repasar de manera sintética el vocabulario básico de Hannah Arendt como aparece en su célebre ensayo The Human Condition (La Condición Humana).

\section{EL VOCABULARIO BÁSICO DE LA CONDICIÓN HUMANA}

La Condición Humana es un ensayo filosófico escrito originalmente en inglés y publicado en los Estados Unidos en 1956. Algunos años después, Arendt misma escribió una versión en alemán que fue publicada en 1960 bajo el título Vita Activa. La versión en alemán no es una mera traducción de la versión en inglés, aunque no se aprecian diferencias significativas en ambos textos. Naturalmente, la versión en alemán presenta una mayor fuerza expresiva, dado que se trata de su lengua materna ${ }^{1}$.

El propósito de La Condición Humana es simple en apariencia: pensar en nuestra manera de actuar en el presente ${ }^{2}$. A fin de responder a esta interrogante, Arendt se embarca en una épica filosófica: una gran narrativa que recorre la Grecia clásica, la Ilustración, y el complejo mundo de la postguerra, derivado de la Segunda Guerra Mundial, la Shoa y la consolidación de la Unión Soviética.

Tal y como sucede en la Ilíada, la épica filosófica de La Condición Humana no tiene un final feliz. Arendt no ofrece respuestas a las perplejidades de su época, ni mucho menos da "recetas" que nos ayuden a superar la adversidad. Por el contrario, Arendt concluye su impresionante tour de force con un catálogo de ansiedades propias de la guerra fría: la posibilidad cercana de la aniquilación de la vida en el planeta tierra, provocada por un conflicto nuclear; o bien la alternativa sinsentido de la recién aparecida sociedad de consumo, aquello que ella llama "la victoria del animal laborans"3.

1 Para una idea general de los datos biográficos de Hanna Arendt, véase Sontheimer, K. (2006) y Young-Bruehl E. (1982). También es útil el capítulo dedicado a la formación intelectual de Hannah Arendt en Pitkin H.F. (1995), cap. 3.

2 Véase Arendt, H. (1998), cap. 5.

3 Véase Arendt, H. (1998), cap. 5. 
La imponente estructura de La Condición Humana se fundamenta en una sólida base de oposiciones conceptuales. La más básica de estas oposiciones es la que se da entre necesidad y libertad. De esta oposición se deriva la distinción fundamental entre la naturaleza -el ámbito de la necesidad, por una parte- y el mundo humano - el ámbito de la libertad. La naturaleza antecede al ser humano y no lo requiere para existir. En tanto que seres vivientes, somos parte de la naturaleza. Por el contrario, el mundo es una construcción humana, es nuestro hábitat. El mundo depende de nosotros para aparecer y para permanecer. El mundo existe ciertamente dentro de la naturaleza, pero no es idéntico a ella.

La naturaleza es el ámbito de la necesidad. La necesidad cósmica prevalece dentro del universo y rige el movimiento regular de los planetas, las estrellas y otros cuerpos celestiales y galaxias. La necesidad cósmica se manifiesta también a escala planetaria en la Tierra a través de los movimientos de rotación y traslación con sus efectos del día y la noche, y las estaciones del año respectivamente. Así, la necesidad rige también la vida en la Tierra, tanto el ecosistema terrestre como la vida de cada uno de los vivientes que la habitan. En términos generales todas las especies de vivientes están sujetas al ciclo de generación y corrupción, nacimiento y muerte. Para Arendt, el ecosistema terrestre carece de cualquier sentido trascendente y se limita a ser una permanente iteración del ciclo de generación y corrupción ${ }^{4}$.

Asimismo, el cosmos en cuanto ecosistema terrestre, según Arendt, está impregnado por la necesidad y es susceptible de ser descrito en sus respectivos funcionamientos a partir de leyes universales y necesarias. Tal visión no coincide con lo que la ciencia reciente nos dice sobre el universo y sobre la vida en nuestro planeta. Sabemos que la vida en la tierra es desde muchas perspectivas un hecho extraordinario 5 , un "milagro", precisamente en el sentido en que Arendt entiende los milagros propios de la acción humana. La vida en la Tierra, es una novedad en el universo, una novedad que no estaba garantizada por las condiciones del entorno inmediato $^{6}$.

En ese sentido, la oposición radical entre naturaleza y mundo, entre las actividades propias de la vida natural no específicamente humana y aquellas propias de la construcción de un mundo no animal, es una oposición que se encuentra en el corazón de la crítica que Arendt hace de las labores de supervivencia.

\footnotetext{
4 Véase Arendt, H. (1981), pp. 89-91; Arendt, H. (1998), pp. 96-98.

5 Véase Behe, M. J. (2000), pp. 113-122.

6 Véase Meyer, S. C. (2000), pp. 53-112.
} 
Todos los vivientes están subyugados por la necesidad, pero solo el ser humano es capaz de alcanzar una cierta emancipación de este ciclo y pasar al ámbito de la libertad. Y sólo el ser humano padece las necesidades fisiológicas como compulsorias y limitantes de su libertad. El resto de los vivientes se encuentra inmerso de manera inexorable en el ciclo de la vida y la muerte; el ser humano en cambio experimenta muchas veces tanto la muerte como las constricciones propias de su animalidad como límites impuestos a su afán de libertad.

Dado que Arendt asocia la noción de naturaleza con la noción de necesidad, evita explícitamente hablar de una "naturaleza humana". De existir, tal naturaleza haría imposible el factum de la libertad humana. Por ello Arendt prefiera hablar de la "condición humana" que para ella es el modo como ha sido dada la vida a los seres humanos en la Tierra? ${ }^{7}$ Los seres humanos estamos condicionados, pero no determinados por nuestra animalidad y por el hecho de vivir en la tierra. Sumada a esta primera oposición entre libertad y necesidad, Arendt distingue dos formas básicas de la vida humana:

En primer lugar, está la vita contemplativa que corresponde la vida teórica en el sentido original del verbo $\theta \varepsilon \omega \rho \varepsilon \tilde{v}$ que quiere decir precisamente "contemplar". Quienes se abocan a esta forma de vida se interrogan por las grandes cuestiones de la filosofía de la naturaleza, la ontología y la metafísica; pero su capacidad para pensar y entender acontecimientos políticos históricos específicos es, según Arendt, muy limitada. Por eso los filósofos no han entendido en profundidad la "vida activa" ni tampoco la actividad más importante de la vida activa, a saber, la política ${ }^{8}$.

Arendt acierta al subrayar la importancia de los acontecimientos políticos para reflexionar sobre la praxis humana. Lo curioso es que su defensa de la vita activa es eminentemente teórica y abstracta, limitación que ella misma llegaría a aceptar $^{9}$. Esto se manifiesta sobre todo en la reducción de todas las actividades humanas no teóricas dentro de las tres simples categorías: labor, trabajo (o fabricación) y acción. Cada una de estas actividades surge de una condicionante específica; cada una da lugar a su propio "escenario" (ámbito de despliegue de la actividad); cada una genera también sus propios productos o efectos; y cada una demanda de la persona habilidades o capacidades específicas.

7 Véase Meyer, S. C. (2000), pp. 10-11.

8 Véase Arendt, H. (1981), pp. 18-21; Arendt, H. (1998), pp. 12-15.

9 "The main flow and mistake of The Human Condition is the following: I still look at what is called in the traditions the vita activa from the viewpoint of the vita contemplativa, without ever saying anything real about the vita contemplativa. Now I think that to look at it [at the vita activa] from the vita contemplative is already the first fallacy." Arendt, H. (1979), p. 305. 
Los escenarios de cada una de las actividades se definen por el grado de "publicidad" de cada una de ellas. El grado de publicidad se puede entender como la susceptibilidad de cada una de las actividades para tener lugar en la presencia de un "público", es decir, de un grupo de personas no vinculadas por lazos familiares o de amistad con los ejecutores de la acción. El ámbito más público es la esfera política, a saber, aquel espacio donde tiene lugar la política: la discusión y deliberación sobre la vida en común. Tal espacio puede representarse con el ágora

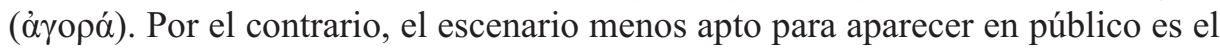
ámbito doméstico, es decir, el ámbito familiar del hogar (oỉí́a).

El tipo de productos o efectos se definen de acuerdo con su durabilidad y con el impacto que tienen en la transformación o preservación del mundo humano. Los productos de la labor son esencialmente bienes perecederos o bienes de consumo; mientras que los productos del trabajo están hechos para durar y son por ello objetos de uso. Los "productos" o efectos de la acción no son tangibles ni durables en un sentido material; su durabilidad se refiere más bien al impacto que tienen en la organización de la vida en común.

Es muy amplio el rango de habilidades y capacidades requeridas para llevar a cabo cada una de estas actividades, y va desde cualidades que compartimos con prácticamente cualquier mamífero superior, pasando por habilidades técnicas (que quizá algunos animales no humanos superiores también poseen), hasta habilidades políticas, que en opinión de Arendt son específicamente humanas.

La labor surge de nuestra condición animal y comprende todas aquellas actividades realizadas con el fin de asegurar la supervivencia del individuo y de la especie. Actividades tales como la nutrición, la reproducción, el descanso o las actividades de higiene individual ${ }^{10}$. Los productos de la labor son bienes perecederos cuyo consumo es necesario para el sostenimiento de la vida, bienes tangibles como los alimentos que consumimos en sentido literal para conservarnos con vida $^{11}$. Salta a la vista que, dada esta descripción, muchas especies de animales superiores serían también capaces de laborar.

En el caso de los seres humanos, que son capaces de vivir en el ámbito privado y en el público, la esfera privada es el espacio propio de las actividades de la labor. Arendt piensa que estas actividades deben realizarse fuera de la mirada pública. Las actividades propias de la labor son extenuantes por la exigencia física y el desgaste que causan, pero más allá de eso no son demandantes en el sentido intelectual. El ser humano, en tanto que laborante, es un animal laborans.

10 Arendt, H. (1979), p. 7.

11 Arendt, H. (1979), p. 96. 
Puesto que las actividades de la labor están encaminadas exclusivamente al sostenimiento de la vida, se encuentran insertas dentro del ciclo de generación y corrupción que caracteriza la vida en la Tierra. Son actividades inevitables y molestas, pero carentes de sentido. Si la condición animal está en el origen de la labor, la condición que Arendt llama "mundaneidad" (worldiness) está en el origen de la actividad de la fabricación (herstellen) o el trabajo (work). El mundo es fabricado por los seres humanos a partir de la transformación de la naturaleza. Gracias a la tecnología, la técnica, la aplicación de las ciencias y las artes construimos un mundo físico de ciudades, caminos, canales, presas, carreteras, etc. Este mundo nos permite sobrevivir y vivir bien.

Los productos del trabajo son la incontable variedad de artefactos, bienes manufacturados y estructuras fabricadas por los seres humanos. Las actividades del trabajo parecen tener lugar en un espacio entre lo público y lo privado, como los talleres de un herrero o un carpintero y en general de los artesanos en las ciudades de la Edad Media. Espacios que no son privados como una casa, pero tampoco de acceso libre como un mercado, aunque sí están abiertos al público. Las habilidades requeridas para el trabajo son las propias de las artes y las técnicas. En contraste con la labor, muchas de estas habilidades son exclusivas del ser humano; e incluso, en el improbable caso de que pudiéramos atribuir habilidades propias del trabajo a otros mamíferos superiores, el grado de maestría y complejidad de las habilidades humanas técnicas y artísticas no es comparable con las capacidades de ninguna otra especie animal ${ }^{12}$. En tanto que es capaz de transformar la naturaleza y construir un hábitat dentro de ella, el ser humano es un homo faber ${ }^{13}$.

Por último, de la condición de pluralidad surge la acción. La pluralidad es el hecho de que cada ser humano es singular y único, pero al mismo tiempo comparte algo común con toda la humanidad. La simultaneidad de nuestra singularidad y nuestra vinculación común es la condición de pluralidad ${ }^{14}$. En opinión de Arendt, las actividades de la acción son las más nobles de las actividades dentro de la vita activa. Es a través de la acción que los seres humanos son capaces de plenificar su libertad. Las actividades de la acción tienen lugar en el ámbito público: ese espacio físico simbolizado por la referida ágora, la plaza pública. Un lugar abierto para cualquiera, que nos pertenece a todos colectivamente, pero a nadie con exclusividad.

12 Arendt, H. (1979), p. 10.

13 Arendt, H. (1979), p. 15.

14 Véase Arendt, H. (1981), pp. 14-16 y pp. 164-164; Arendt, H. (1998), pp. 175-176. 
Ciertamente, la acción demanda habilidades políticas específicas, como la capacidad de persuadir o convencer a otros, la capacidad de trabajar en equipo, la capacidad de dialogar para llegar acuerdos, la empatía y por supuesto la sabiduría práctica (o sensatez) y la imaginación política:

"La acción es la única actividad de la Vita activa que se da directamente entre los seres humanos sin mediación de la materia, ni materia natural ni cosas. La condición fundamental que le corresponde es el factum de la pluralidad, es decir, el hecho de que sobre la tierra no uno, sino muchos seres humanos viven sobre la tierra y habitan el mundo"15.

La acción trasciende los límites de la necesidad natural, en primer lugar, porque las actividades de la acción no están ni orientadas a la supervivencia ni son resultado del afán natural de saciar nuestras necesidades fisiológicas; pero también son actividades que escapan a motivaciones que podríamos considerar tangibles o cuantificables, como el afán de lucro. Esta doble trascendencia ocasiona que las acciones sean impredecibles tanto en su génesis como en sus consecuencias. Las acciones son inesperadas, novedosas, sorprendentes y singulares. Las acciones transforman el mundo y al mismo tiempo revelan de forma radical la singularidad y unicidad del actor. Las acciones son la esencia de la política y por ello son la más clara expresión de la libertad humana.

A pesar de su importancia para la plenificación de la libertad, no es fácil de definir bien a bien qué entiende Arendt por acción. Si asumimos que las acciones requieren un escenario en el ámbito público, podríamos definir acción como todas aquellas discusiones, iniciativas y decisiones no violentas y politicas que impactan al ámbito público y transforman la organización de la vida en común. Ejemplos de acciones serían el discurso pronunciado por Winston Churchill el 13 de mayo de 1940 y recordado por su oferta de "sangre, esfuerzo, sudor y lágrimas"; o los discursos que transmitía desde Londres Charles de Gaulle a sus conciudadanos en la Francia ocupada; o la negociación de Konrad Adenauer en 1955 para liberar diez mil prisioneros alemanes del poder soviético; también el gesto de Willy Brandt de arrodillarse en Varsovia frente al monumento a los judíos asesinados en el holocausto. Una acción sería también el discurso de I have a dream de Martin Luther King; o el gesto del Papa Juan Pablo II de besar el suelo polaco durante su primera visita oficial a ese país; o el canto de Amazing Grace del presidente Barack Obama durante el servicio religioso por los atentados de Charles-

15 "Das Handeln ist das einzige Tätigkeit der Vita activa, die sich ohne die Vermittlung von Materie, Material und Dingen direkt zwischen Menschen abspielt. Die Grundbedingung, die ihr entspricht, ist das Faktum der Pluralität, nämlich die Tatsache, daß nicht ein Mensch, sondern viele Menschen auf der Erde leben und die Welt bewölkern". Arendt, H. (1981), p. 14. 
ton en 2016; una acción o una serie de acciones sería también el episodio ocurrido en el parlamento español durante el fallido golpe de Estado del 23 de febrero de 1981, narrado magistralmente en Anatomía de un instante, por Javier Cercas.

Todos estos gestos "políticos" son únicos; tienen un impacto simbólico y político mayúsculo; son iniciativas novedosas, que revelan el carácter singular de quienes los realizaron; son gestos que transformaron el mundo. Sin embargo, los ejemplos también nos dejan claro que las personas comunes y corrientes no estamos en posición de realizar gestos de tal envergadura. Incluso Arendt llegó a afirmar que ella misma había "actuado" en muy pocas ocasiones durante su vida ${ }^{16}$.

Si la libertad se alcanza a través de las acciones, y solo las acciones permiten conocer quiénes somos, la plenificación humana no estaría abierta para la mayoría de los seres humanos. Comparadas con la magnanimidad y la libertad de la acción, las actividades de la labor carecerían de toda importancia política e incluso personal; mientras que las actividades del trabajo serían tolerables meramente como medios para construir un escenario adecuado para el despliegue de la acción y la gestación de la vida pública.

\section{DISTINCIÓN ENTRE LABOR Y TRABAFO}

Es difícil sobrevalorar la radicalidad de la propuesta de Arendt sobre la diferencia entre labor y trabajo. Arendt afirma que todas las lenguas europeas, desde el griego clásico hasta el alemán, el inglés y el francés (incluso el castellano) han distinguido lingüísticamente entre estas dos actividades. Para Arendt, la mayoría de las teorías filosóficas relativas a las actividades de la labor y el trabajo no consideran tal distinción, a pesar de ser fundamental para entender ambas actividades y aún vigente en los usos comunes de las lenguas. ${ }^{17}$ En su opinión, la mayoría de las teorías de su tiempo respecto a la labor adolecen de una idealización académica (akademische Idealisierung) que les impide entender el trabajo ${ }^{18}$.

Como hemos mencionado, el trabajo deriva de nuestra condición mundana; del hecho de que somos capaces de transformar la naturaleza mediante la fabrica-

16 " [...] I think I understood something of action precisely because I looked at it from the outside, more or less. I have acted in my life, a few times, because I couldn't help it. But that is not what my primary impulse is"; Hill, M. A. (ed.) (1979), pp. 303-304.

17 Véase Arendt, H. (1981), pp. 76-77.

18 Véase la larga nota en: Arendt, H. (1981), pp. 343-344, nota 75. Esta nota ejemplifica también los pequeños matices diferentes entre la versión en inglés (véase Arendt H, (1998), pp. 127-28. Nota 75) y la versión en aleman aquí citada. Pues la versión en inglés no menciona el akademische Idealisierung de estas teorías, simplemente habla de "idealizaciones y prejuicios". 
ción: "En este mundo de cosas encuentra su hogar la vida humana, vida que por naturaleza se encuentra en la naturaleza sin hogar. [...] La condición fundamental bajo la cual se da la actividad del fabricar es la mundanidad (Weltlichkeit), es decir, la dependencia que tiene la vida humana de un mundo de objetos (Gegenständlichkeit) y de objetividad (Objektivität)"19.

Trabajar permite la construcción de un hábitat en medio del mundo natural. Según Arendt, los productos del trabajo se distinguen radicalmente de los productos de la labor por su durabilidad y resistencia a la corrupción y al desgaste, es decir, por su permanencia ${ }^{20}$. Por el contrario, la labor se deriva de nuestra condición animal y engloba todas aquellas actividades que debemos realizar para mantenernos con vida y salud: "La actividad de la labor corresponde al proceso biológico del cuerpo humano, que se alimenta de cosas naturales en su desarrollo espontáneo, sus procesos bioquímicos, y su degeneración; cosas naturales que son generadas y preparadas por la labor, para ser administradas como víveres al organismo vivo. La condición fundamental (Grundbedingung) bajo la cual se dan las actividades de la labor, es la vida misma"21.

Por razón de nuestra "condición animal", formamos parte del orden natural y nuestra vida transcurre marcada por elementos propios de todas las especies de animales superiores de nuestro planeta: gestación, nacimiento, desarrollo, reproducción, envejecimiento y muerte. En tanto que animal, el ser humano debe saciar las exigencias propias de su organismo - alimentación, descanso, higiene, reproducción. El ser humano es un "animal laborante" más en la tierra, un animal laborans.

Los frutos de la labor son principalmente los alimentos, productos perecederos de poca permanencia que, de no ser consumidos por los seres humanos, volverán de todas formas al ciclo natural e infinito de generación y corrupción que rige la vida de los organismos en nuestro planeta. Arendt llama a estos víveres

19 "Das Herstellen produziert eine künstliche Welt von Dingen, die sich den Naturdingen nicht einfach zugesellen, sondern sich von ihnen dadurch unterscheiden, daß sie der Natur bis zu einem gewissen Grade widerstehen und von den lebendigen Prozessen nicht einfach zerrieben werden. In dieser Dingwelt ist menschliches Leben zuhause, das von Natur in der Natur heimatlos ist[...] die Grundbedingung, unter der die Tätigkeit des Herstellens steht, ist Weltlichkeit, nämlich die Angewiesenheit menschlicher Existenz auf Gegenständlichkeit und Objektivität"; Arendt, H. (1981), p.14.

20 Arendt, H. (1981), Apartados 28 y 19.

21 "Die Tätigkeit der Arbeit entspricht dem biologischen Prozeß des menschlichen Körpers, der in seinem spontanen Wachstum, Stoffwechsel und Verfall sich von Naturdingen nährt, welche die Arbeit erzeugt und zubereitet, um sie als die Lebensnotwendigkeiten dem lebendigen Organismus zuzuführen. Die Grundbedingung, unter der die Tätigkeit des Arbeitens steht, ist das Leben selbst”; Arendt, H. (1981), p. 14. Todas las traducciones son de Fernando Galindo. 
"bienes de consumo", porque usarlos implica consumirlos y consecuentemente aniquilarlos ${ }^{22}$.

La crítica a las labores de supervivencia aparece en La Condición Humana en el capítulo tercero, hacia el final del apartado trece que lleva por título "La labor y la vida" (Die Arbeit und das Leben). El capítulo inicia con el apartado once, titulado "La labor de nuestro cuerpo y el trabajo de nuestras manos" ("Die Arbeit unseres Körpers und das Werk unserer Hände", con comillas en original), al cual sigue el apartado doce bajo el título "El mundo y su carácter de cosa" (Die Dinghaftigkeit der Welt). Antes de entrar en el análisis minucioso de dicha crítica, es indispensable señalar una ambigüedad lingüística en la relación que Arendt establece entre las nociones de trabajo y la labor.

Recordemos que la primera versión de la obra en cuestión fue escrita en inglés y fue publicada en 1958. La versión alemana vio la luz hasta 1960. En la versión original en inglés el contraste se establece entre "labor" y "work", que corresponde según Arendt al alemán "Arbeit" y "Herstellen" respectivamente. El problema de esta correspondencia sale a relucir cuando traducimos directamente de estas lenguas al castellano. Puesto que si traducimos del inglés la correspondencia sería "labor" / "labor"; "work" / "trabajo," la correspondencia en alemán sería "Arbeit" / "trabajo"; "Herstellen" / "fabricación"²3. Si bien es posible traducir "Arbeit" al inglés con la palabra "labor", la correspondencia más común de "Arbeit" en inglés es "work" y de ninguna manera puede traducirse "work" por "Herstellen" como pretende Arendt. Lo mismo sucede en castellano: la traducción más común de "Arbeit" es "trabajo", y no "labor"; y la traducción ordinaria de "Herstellen" obviamente es "fabricación" y de ninguna manera "trabajo", como podemos ver en la siguiente tabla:

Tabla 1.

\begin{tabular}{l|l|l|l}
\hline Término original en inglés & Traducción alemana & $\begin{array}{l}\text { Traducción del inglés } \\
\text { al castellano }\end{array}$ & $\begin{array}{l}\text { Traducción del alemán } \\
\text { al castellano }\end{array}$ \\
\hline Labor & Arbeit & Labor & Trabajo \\
\hline Work & Herstellen & Trabajo & Fabricación \\
\hline
\end{tabular}

22 Véase Arendt, H. (1981), Apartado 11.

23 La ambigüedad en el uso que Arendt hace del verbo "to work" ya ha sido señalada: "In American English it remains more or less the case that the verbal form of "work" is still "in play." It is still used more or less synonymously with "labor". However, contrary to Arendt's claim, it too has shed much of its "original" significance of pain and labor"; Major R. W. (1979), pp. 150-151, nt. 4. Aunque Major no menciona la diferencia entre la versión en inglés americano y la versión en alemán. 
"Work," "Arbeit" y "Trabajo" son todas palabras genéricas que agrupan dentro de su semántica todas las formas de trabajo posibles. Si aceptáramos la noción de labor que propone Arendt, la labor sería una forma de trabajo orientado a satisfacer las necesidades vitales. Y de igual forma "Herstellen" ("fabricación") sería otra forma de trabajo orientado a la producción de objetos de uso que buscan ser durables.

Esta precisión es relevante, pues una de las tesis centrales de Arendt es que numerosos filósofos, en su devoción por la vida contemplativa, han obviado la evidente diferencia entre labor y trabajo: atrapados en la maravilla de las construcciones filosóficas, han dejado del lado, nos dice Arendt, experiencias humanas fundamentales que muestran esta distinción y que se traducen en el uso común de tal distinción en las más variadas lenguas, desde el griego clásico hasta el inglés, el alemán y el francés contemporáneos ${ }^{24}$.

En un admirable esfuerzo de erudición y síntesis, Arendt recorre diversas clasificaciones de la labor, que en realidad corresponden a nuestra noción genérica de "trabajo." Arendt distingue entre: labor improductiva y productiva $a^{25}$; labor calificada y no calificada (gelernte Arbeit und ungelernte Arbeit); $;{ }^{26}$ labor de la mente y la labor de las manos (Kopf- und Handarbeit) ${ }^{27}$; la labor fisica y labor intelectual (Körperlicher und geistiger Arbeit) ${ }^{28}$. En todos estos casos, vemos cómo el castellano hablaría del "trabajo productivo e improductivo"; "trabajo calificado y no calificado", etc.; y lo mismo pasaría en un uso ordinario del inglés.

\section{EL PROBLEMA DE LA LABOR}

Un análisis cuidadoso de las reflexiones de Arendt muestra que su distinción entre labor y trabajo no tiene que ver en primera instancia con la disposición individual de la persona que realiza la actividad, sino con el resultado objetivo o el producto de esa actividad. Los frutos de la labor son perecederos e incapaces por tanto de dotar de estabilidad al ámbito humano. Pero los objetos fabricados resisten (al menos por un tiempo) a la corrupción natural que padecen los seres vivos y con ello ofrecen la durabilidad y estabilidad que permiten la existencia de un mundo humano, yuxtapuesto en el ámbito natural. Mundo que constituye la condición de posibilidad y el escenario idóneo para las actividades humanas relacionadas con la acción.

\footnotetext{
24 Véase Arendt, H. (1981), Cap. III, Notas 3, 5, 7, 8.

25 Véase Arendt, H. (1981), p. 81.

26 Véase Arendt, H. (1981), p. 82.
} 
De esta forma, la labor forma parte del ciclo sin fin de la naturaleza cuyo único sentido es el sostenimiento del proceso de la vida del ecosistema. Un ciclo que, para Arendt, no da lugar a la realización personal de que somos capaces los seres humanos por tres motivos:

1. Porque carece de toda posibilidad de singularidad: la labor solo se encarga de asegurar la preservación de la vida de la especie y no las acciones de los individuos.

2. Porque carece de libertad: el ciclo sigue una regularidad invencible y es de una necesidad absoluta. La labor de los seres humanos forma parte de un proceso recurrente e infinito de supervivencia en el que a nivel individual se evocan los movimientos recurrentes cósmicos y los ciclos infinitos de un ecosistema.

3. Porque la actividad de la labor no deja nada permanente tras de sí, nada memorable.

Sin embargo, las actividades de la labor son indispensables para la conservación de nuestros cuerpos y de nuestro mundo. De otra forma el interminable proceso de generación y corrupción que constituye la vida de la naturaleza irrumpiría en el mundo construido por los seres humanos y lo volvería inútil para cumplir con las funciones que le corresponden ${ }^{29}$.

Podemos afirmar que las labores de conservación del cuerpo y del mundo representan un cierto agobio si se les compara con la urgencia que aqueja a las labores propias de la alimentación. Las labores de conservación en estricto sentido no producen nada, a diferencia de otras actividades de la labor que producen alimentos perecederos; sin embargo, la relación de estas labores de conservación con el mundo es evidentemente estrecha (einem erheblich engeren Bezug zu der $W e l t)^{30}$, ya que se encargan de impedir que el mundo sea "devorado" por la naturaleza.

Por tal motivo, Arendt afirma que dichas labores de conservación han merecido las alabanzas de sagas y mitos a lo largo de la historia, tanto la Grecia antigua -Arendt menciona como ejemplo una de las tareas encomendadas a Hércu-

27 Véase Arendt, H. (1981), p. 82

28 Véase Arendt, H. (1981), p. 83.

29 Pensemos en la Gran Pirámide de Cholula, conocida también como Tlachihuealtépetl, en el estado de Puebla (México). Una pirámide inmensa (cuatro millones quinientos mil metros cúbicos de volumen) que fue construida poco a poco a lo largo de cientos de años. Cerca del año mil de nuestra era la pirámide fue abandonada y poco a poco la vegetación y la hierba fueron cubriéndola hasta formar una aparente montaña inhóspita; no fue sino a mediados del siglo XX que la pirámide fue "encontrada" por los arqueólogos y redescubierta de modo parcial. 
les, aquella de limpiar los establos de Augías-, como en los cantares del medioevo, que exaltaron la fuerza heroica y la gran valentía demandada por las labores en general.

A pesar de la opinión de los clásicos y los medievales Arendt afirma que, "en los hechos", la labor no tiene ningún carácter heroico; y es más bien un conjunto de pequeñas batallas cotidianas llevadas a cabo por el cuerpo humano (der menschliche Körper) para conservar y limpiar al mundo ${ }^{31}$, La resistencia que demandan tales labores no está relacionada con la virtud de la valentía, pues se trata de actividades al margen de cualquier peligro. Aquello que hace extenuantes estas labores no es la exposición a algún riesgo, sino más bien su infinita iteración:

"Empero, fácticamente (faktisch) queda poco de tales actos heroicos en la pequeña lucha cotidiana que el cuerpo humano (der menschliche Körper) tiene que realizar para conservar y limpiar el mundo; no es valentía la resistencia (Ausdauer) que tal lucha demanda para empezar cada día de nuevo a ordenar lo que el día anterior ha desordenado, y no es tampoco ningún peligro lo que hace este esfuerzo tan extenuante; lo extenuante se debe más bien a su interminable repetición (endlose Wiederholung)"32.

La monotonía, la repetición, el tedio y la frustración son las características que acompañan a las labores domésticas. Por ello, en la antigüedad clásica las labores domésticas eran impuestas a los esclavos -hombres y mujeres-y a las mujeres libres -esposas, madres e hijas- a fin de liberar a unos pocos varones y permitirles alcanzar y ejercitar la libertad política a través de hazañas y gestas políticas $^{33}$. Esta peculiar noción de labor proviene de una comprensión particular de necesidad, como veremos a continuación.

\section{LABORES DOMÉSTICAS COMO ESCLAVITUD ANTIGUA Y MODERNA}

La noción específica que Arendt tiene de la palabra necesidad remite a la no-

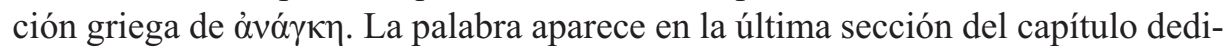

30 Véase Arendt, H.(1981), p. 92.

31 Véase Arendt, H.(1981), pp. 91-92.

32 "Von solchen Heldentaten ist allerdings faktisch in dem täglichen Kleinkampf, den der menschliche Körper um die Erhaltung und Reinhaltung der Welt zu führen hat, wenig zu spüren; die Ausdauer, deren es bedarf, um jeden Tag von Neuem aufzuräumen, was der gestrige Tag in Unordnung gebracht hat, ist nicht Mut, und es ist nicht Gefahr, was diese Anstrengungen so mühevoll macht, sondern ihre endlose Wiederholung"; Arendt, H.(1981), p. 92. Nótese que Arendt habla explícitamente del cuerpo humano como aquel que realiza la labor, y no la persona en su integridad.

33 Véase Arendt, H. (1998), pp. 82-83. 
cado a la actividad de la labor en La Condición Humana, y se menciona únicamente en una nota a pie de página que se refiere a una cita famosa de la Iliada. Cita que Simone Weil eligió como epígrafe para su importante obra La Condition Ouvrière, publicada en $1951^{34}$. Sin embargo, en su obra Denktagebuch, el diario

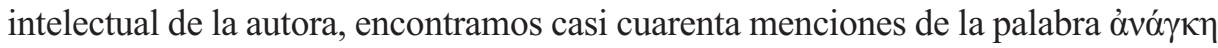
y sus derivados. La primera mención aparece en mayo de 1951 y la última in septiembre de 1969. Tres significados de ỏvó $\gamma \kappa \eta$ tienen especial relevancia para la concepción que Arendt tiene de la necesidad y la labor:

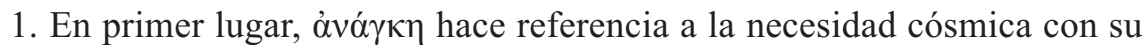
consecuente necesidad física y que en la biología se traduce como una fuerza de compulsión. Esta necesidad rige tanto en el cosmos como en la Tierra.

2. Un segundo significado es el de ả $v \alpha ́ \gamma \kappa \eta$ como una fuerza violenta: algo impuesto violentamente a través de una fuerza exógena, como la fuerza del destino que nos es impuesta por los dioses; o como la esclavitud, precisamente.

3. El tercer significado de ảvó $\gamma \kappa \eta$ es cercano al segundo: ảvó $\gamma \kappa \eta$ entendida como una fuerza de coerción y de ejecución ${ }^{35}$.

Una somera revisión de estas tres entradas en el diario intelectual de Arendt saca a la luz la estrecha relación entre la necesidad ( $\alpha \dot{\alpha} \gamma \kappa \eta)$ la labor y la esclavitud. Una entrada de febrero de 1952 afirma: "Solo el esclavo era un laborante (i.e. "Arbeiter", nótese que la traducción ordinaria sería "trabajador"), y todo laborante (Arbeiter) era un esclavo" ${ }^{\text {"3 }}$. Arendt afirma además que: "Quien labora (arbeitet) a fin de obtener $\dot{\alpha} v \alpha \gamma \kappa \alpha i ̃ \alpha$ para sí mismo, no es libre. Quien labora, a fin de obte-

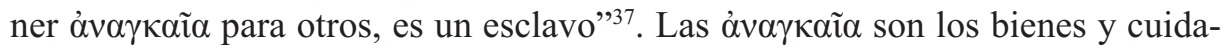
dos indispensables para la supervivencia. Las actividades orientadas a la obten-

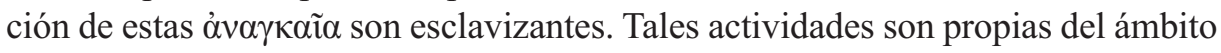
doméstico: preparación de alimentos, cuidado de los hijos y los ancianos, cuidado del propio cuerpo, descanso, limpieza y mantenimiento del hogar.

En consecuencia, las mujeres libres del mundo clásico a cargo del ámbito doméstico no eran diferentes a los esclavos. Puesto que la libertad sólo es posible

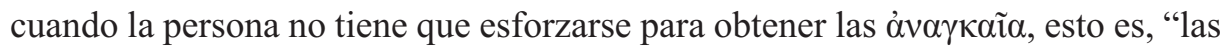
cosas necesarias para la vida", como afirma Arendt en la misma entrada: "La li-

34 Véase Arendt, H. (1998), p. 131, nota 83.

35 Pape, W. (1914), Vol. 1, p. 183.

36 "Nur der Sklave war ein Arbeiter, und jeder Arbeiter war ein Sklave". Arendt, H. (2002), VIII, entrada 6, p. 183.

37 "Wer arbeitet, um für sich selbst $\alpha$ " $\alpha \gamma \kappa \alpha i ̃ \alpha$ zu beschaffen, ist nicht frei. Wer arbeitet, um für Andere àv $\alpha \gamma \kappa \alpha i ̃ \alpha$ zu beschaffen, ist ein Sklave”. Arendt, H. (2002), VIII, entrada 6, p. 183. 


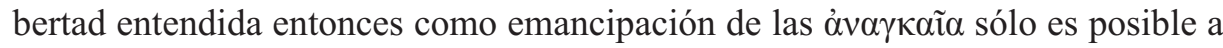
través de la esclavitud"38

En una entrada más tardía datada en abril de 1952, Arendt describe la situa-

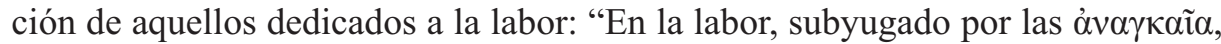
el ser humano se encuentra siempre aislado y acosado por la preocupación y la angustia" 39. Y un poco más adelante en la misma entrada añade: "En tanto que laborantes (Arbeitende, recalcamos de nuevo que la traducción más natural al espa-

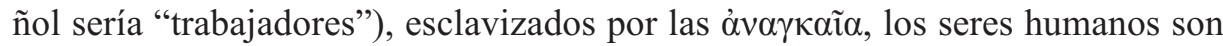
casi como animales" ${ }^{\prime 4}$. Las personas dedicadas a actividades de la labor son de facto esclavos; aun si de iure se les considera hombres y mujeres libres.

Pero la entrada más reveladora para entender la relación entre la necesidad y la labor aparece un poco antes en el diario intelectual. En ella encontramos la misma referencia al pasaje de la Iliada citado en La Condición Humana y en el libro de Simone Weil. Se trata de la primera entrada datada en abril de 1952. Es una entrada extensa, así que nos limitaremos a citar únicamente las frases más im-

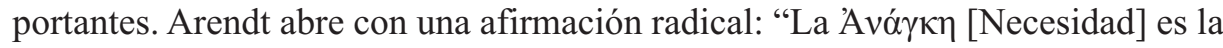
diosa de las $\dot{\alpha} v \alpha \gamma \kappa \alpha i ̃ \alpha$ [las cosas necesarias para sostener la vida] y como tal es temible" ${ }^{41}$. Sigue una cita sin traducción del libro sexto de la Iliada, que contiene la famosa frase que Héctor dirige a su esposa Andrómaca: “ $\pi$ ó $\lambda \lambda$ ” $\alpha \varepsilon \kappa \alpha \zeta o \mu \varepsilon ́ v \eta$,

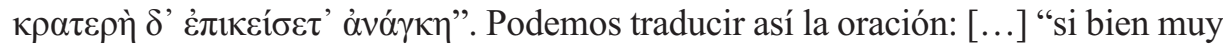
a tu pesar, fuertemente se te impondrá de todas formas la necesidad".

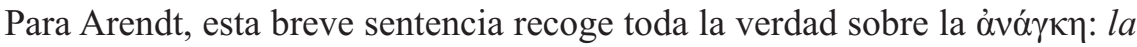
necesidad reina sobre la humanidad. Reina de manera violenta y muy en contra de nuestros deseos. Simone Weil alcanzó a vislumbrar esta situación, y sin embargo no quiso o no pudo ir lo suficientemente lejos para llegar a la conclusión obvia:

38 "Freiheit ist also als Emanzipation von den $\alpha$ v $\alpha \gamma \kappa \alpha i ̃ \alpha$ nur möglich durch Sklaverei”. Arendt, H. (2002), VIII, entrada 6, p. 183. La radicalidad de esta cita puede resultar molesta, pero el texto no deja espacio a la ambigüedad. El texto además recuerda líneas igualmente duras de Rousseau : «Pour vous, peuples modernes, vous n'avez point d'esclaves, mais vous l'êtes; vous payez leur liberté de la vôtre. Vous avez beau vanter cette préférence; j’y trouve plus de lâcheté que d'humanité». Rousseau, J. (1762), p. 303) ["Para ustedes, gente moderna, no hay necesidad de esclavos, y sin embargo ustedes mismos son los esclavos; pagan con la libertad propia el precio de la libertad de los esclavos. En vano se esfuerzan por exaltar esta preferencia; en ella yo encuentro más cobardía que humanidad".]

39 "In der Arbeit, den $\alpha \dot{v} \alpha \gamma \kappa \alpha i ̃ \alpha$ unterworfen, ist der Mensch immer isoliert und von Sorge und Angst getrieben”. Arendt, H. (2002), IX, entrada 3, p. 204.

40 “Als Arbeitende, den $\alpha \dot{v} \alpha \gamma \kappa \alpha \tilde{\alpha} \alpha$ versklavt, sind Menschen fast wie Tiere”. Arendt, H. (2002), IX, entrada 3, pp. 203-4. Underlined in the original.

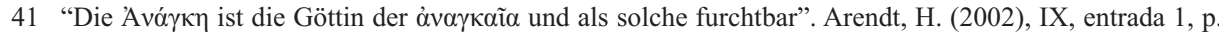
201. 
"Libertad y justicia parecen ser irreconciliables, porque la libertad sólo es posible, cuando lo profundamente constrictor de las $\alpha \dot{v} \alpha \gamma \kappa \alpha \tilde{\alpha} \alpha$ se impone a otros" ${ }^{\prime \prime 2}$.

Sólo a través de la esclavitud es posible alcanzar la libertad política. El origen de la esclavitud no se encuentra en un orden político o de gobierno específico, sino en la naturaleza misma y en el modo en que esta naturaleza regida por la necesidad y la violencia hace sentir su rigor sobre la especie humana: "La subyugación (Versklavung) de seres humanos por otros seres humanos es posible gracias a la subyugación (Versklavung) original del ser humano por parte de las

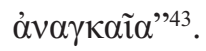

Quizá hemos proscrito la esclavitud, pero no hemos redimido el carácter esclavizante natural (en el sentido de que es parte de la naturaleza cósmica) de las actividades de la labor, de todas aquellas actividades domésticas dedicadas al soste-

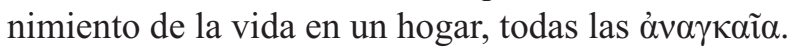

Dado que nos negamos a aceptar la fuerza elemental y violenta de la necesidad, pretendemos que la labor puede gozar de algún tipo de dignidad: "Más aún: A través del reconocimiento de la dignidad de la labor (Arbeit) hacemos inofensiva a la Avó́ $\gamma \kappa \eta$ y con ello a todo aquello que no podemos dominar-la muerte, el sufrimiento, etc., la vieja historia" ${ }^{44}$.

En suma, los antiguos tenían esclavos, esposas e hijas para contener el poder de la necesidad; los modernos tenemos jornaleros, mozos y trabajadoras domésticas (Arendt diría "laborantes", pero equivale a lo mismo) en países pobres como Bangladesh o países en desarrollo como México; también tenemos esposas e hijas. Todos ellos son jurídicamente considerados libres, aunque de facto permanecen bajo el imperio de la necesidad. Se trata de una forma moderna de esclavitud, aunque difícilmente se les reconozca como una forma de esclavitud "suave".

Queda completa así la crítica de Arendt al concepto de labor (humana, propiamente), misma que se resume en los siguientes postulados:

1. La labor se encarga de la conservación del cuerpo y del mundo.

42 "Freiheit und Gerechtigkeit scheinen unvereinbar zu sein, weil Freiheit nur möglich ist, wenn das eigentlich Zwingende der $\grave{\alpha} v \alpha \gamma \kappa \alpha i ̃ \alpha$ auf Andere abgeschoben ist”. Arendt, H. (2002), IX, entrada 1, p. 201. Sentimiento que, como deja ver la previa cita de Rousseau, no es exclusivo de Arendt.

43 "Die Versklavung des Menschen unter den Menschen ist bedingt durch die ursprüngliche Versklavung des

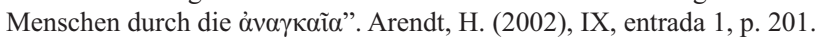

44 "Ferner: Durch die Anerkennung der «Würde der Arbeit» verharmlost man die Avó $\gamma \kappa \eta$ und damit alles, wessen man nicht Herr werden kann -Tod, Leiden etc., die alte Geschichte”. Arendt, H. (2002), IX, entrada 1, p. 201. 
2. Aunque no producen alimentos perecederos, las actividades de conservación y cuidado sí están atrapadas de modo directo en el ciclo interminable de generación y corrupción de la naturaleza.

3. A pesar de tener lugar en el mundo de los seres humanos, la labor y sus actividades no forman parte de éste, ni tampoco forman parte del ámbito público dado que están confinadas al ámbito doméstico privado.

4. Por su carácter privado y obscuro, la labor es esencialmente anti-política y se da fuera del ámbito público.

5. La labor no permite el desarrollo de la individualidad ni la realización personal a través de la participación política. Por eso en el mundo clásico, se condenaba a los esclavos y a las mujeres a realizar las actividades necesarias para el sostenimiento de la vida, a fin de liberar a un puñado de ciudadanos (principalmente varones) para ejercer la ansiada libertad a través de las grandes acciones políti$\operatorname{cas}^{45}$.

\section{BREVE APOLOGÍA DE LA LABOR Y DE LAS LABORES DOMÉSTICAS}

Arendt afirma que su postura respecto a la labor como concepto se deriva de las experiencias humanas fundamentales, y que "en los hechos" es experiencia común el tedio y la frustración que pueden generar las actividades de la labor. Como parte de la clase media alemana y luego norteamericana, Hannah Arendt carecía de "servicio doméstico", y no parece aventurado asumir que estuvo siempre familiarizada con las asperezas de las labores domésticas. Aunado a esto, de pequeña vivió en carne propia la experiencia agotadora de cuidar a su padre enfermo de sífilis ${ }^{46}$.

La vida de los esclavos en los campos de algodón del sur de los Estados Unidos antes de la guerra civil, o de la de los obreros en la revolución industrial británica no parecía ofrecer demasiadas oportunidades para el florecimiento de la libertad, ni para la realización individual. Algo similar podría decirse de la vida de muchas mujeres que trabajan en la maquila en Ciudad Juárez, en México; o de la vida de los millones de laborantes del turbocapitalismo chino.

45 "que la labor corporal es esclavizante, porque es impuesta a causa de las necesidades del cuerpo"; ([...] dass körperliche Arbeit sklavisch ist, weil sie durch die Notdurft des Körpers erzwungen ist); Arendt, H. (1981), p. 78.

46 Arendt tenía cuatro años cuando la enfermedad obligó a su padre a permanecer en cama, cinco cuando su padre fue hospitalizado y siete cuando murió. Como bien señala H. F. Pitkin, la experiencia debió haber sido desgarradora, véase Pitkin, H.F. (1995), p. 66. A pesar de mencionar en el título las labores domésticas ("Housekeeping") este ensayo habla muy poco del tema. 
El yugo de la necesidad parece dominar a la madre que reduce su existencia (aparentemente) a un ciclo de alimentación, limpieza y sueño precario; mientras el padre intenta brindar apoyo moral y mantenerse despierto durante las colaciones nocturnas del recién nacido. Y en la misma noche la niña de ocho años vomita dos veces, obligando al padre a cederle su lugar en la cama, pues es imposible limpiar el colchón a esas horas de la noche; la necesidad agobia igualmente al hijo adolescente que se pasa días enteros a lo largo de varios meses cuidando al padre que sufrió un paro cardiaco y luego respiratorio, esperando que despierte y vuelva de ese limbo entre la vida y la muerte. Lo mismo vale para la familia que acoge a un hijo con parálisis cerebral o espina bífida, o para quien se dedica al cuidado de los padres ancianos... los ejemplos son innumerables.

La dureza de estas experiencias históricas y a la vez cotidianas es incontestable. Empero, es también un hecho que la libertad y la realización personal florecen en condiciones "laborales" extremas: La primera gran novela del gran escritor norteamericano Dave Eggers se gestó en la experiencia del autor al cuidar a su madre enferma de cáncer ${ }^{47}$. Y fue entre los esclavos de raza negra de los Estados Unidos que germinó la semilla que daría lugar al jazz, quizá la forma de expresión musical más libre, más personal, más abierta a la novedad y a la espontaneidad que existe en el mundo. El jazz es la música por excelencia del animal laborans. Esta experiencia histórica por sí sola basta para indicar que es apresurado condenar a la labor como una actividad inherentemente esclavizante, a pesar de que Arendt, como hemos visto, no deja lugar para ambigüedades al respecto.

Pensamos por eso que la concepción de la labor de Arendt presenta tres problemas medulares:

1. Primero, tal parece que Arendt no se acaba de reconciliar con nuestra animalidad humana, con su corporeidad y sus consecuencias; por el contrario, percibe a la animalidad como una carga impuesta a nuestra humanidad. Como si el ser humano fuese un espíritu noble, político e intelectual "montado" sobre un cuerpo pestilente, pasado de peso, enfermizo y controlado por el hambre, el sueño y las demás necesidades.

2. Segundo, da la impresión de que Arendt no dimensiona la relación simbiótica de co-dependencia creadora y positiva entre la vida privada (a saber, el hogar) y el ámbito público; entre lo que ella llamaría el ámbito privado de lo doméstico (el oĩkos) y el ágora, ambas partes esenciales de la polis.

47 Véase Eggers, D. (2000). 
3. Por último, Arendt parece olvidar que las labores de conservación, limpieza y cuidado del mundo se oponen de modo radical a la sociedad de consumo, de producción de lo superficial y de desperdicio, que ella misma critica con enorme pertinencia y acierto ${ }^{48}$.

Para Arendt, la actividad específicamente humana que nos distingue del resto de los animales es la acción política: La humanidad de una persona se descubre ante ella misma y ante los demás cuando toma alguna iniciativa libre en el ámbito público que transforma el mundo. Desde este punto de vista nuestra animalidad es un obstáculo a superar en favor del florecimiento de la acción y, por tanto, es un obstáculo para la realización de nuestra humanidad y de la civilización ${ }^{49}$. Nuestra animalidad nos mantiene atados a las necesidades del cuerpo y con ello nos iguala al resto de los animales ${ }^{50}$.

Hay al menos dos puntos cuestionables en esta noción de animalidad: el primero relacionado con la noción que Arendt tiene del cuerpo; el segundo con las posibilidades de realizar actividades propias de la labor de un modo específicamente humano.

Respecto al cuerpo, Arendt parece entenderlo como una especie de vehículo y no como algo constitutivo del ser humano. Por eso afirma que las labores del cuerpo son esclavizantes, dado que nos vienen impuestas por las necesidades del cuerpo, es decir, por nuestra animalidad. El cuerpo es algo casi "ajeno" a noso$\operatorname{tros}^{51}$.

Por otra parte, Arendt se refiere a las labores de cuidado y limpieza del mundo, como actividades que deben ser realizadas por el "cuerpo humano", es decir, actividades en las que el ser humano no puede ejercitar sus potencias intelectuales y políticas más nobles de manera plena, y por eso, está en cierta medida "ausente" de sí mismo y de su actividad ${ }^{52}$.

Por el contrario, nosotros pensamos que la animalidad es definitoria de nuestra humanidad. Y por tanto hay una vinculación animal humana original que pre-

48 Para una crítica diferente de la noción de Arendt de labor véase Bakan, M. (1979), pp. 49-66. Bakan propone, que labo, trabajo y acción deben entenderse como actividades interdependientes e igualmente necesarias para el ser humano. En nuestra opinión, y como deja claro el Denktagebuch, para Arendt la labor es una forma de esclavitud.

49 Respecto a la necesidad y su impacto anti civilizatorio véase, Arendt, H. (1963) Capítulo II, sobre la cuestión social, y la reveladora cita de Saint Just que sirve como epígrafe y condensa, en capítulo "Los desgraciados, son el poder de la tierra".

50 Véase Arendt, H. (1981), p. 79.

51 Véase Arendt, H. (1981), p. 78

52 Véase Arendt, H. (1981), p. 91. 
cede y demanda a la vinculación humana política. Nuestro cuerpo es el primer vínculo con los otros, un vínculo "animal" que nos une con nuestros padres y parientes y que es precondición de todo vínculo político posterior. Los lazos de sangre preceden a cualquier vínculo político y a cualquier contrato $o^{53}$.

Estamos vinculados a otros desde la concepción, gestación y nacimiento. Iniciamos nuestra vida en otra, en nuestra madre. Necesitamos de otros para venir a la existencia y sobrevivir, así como necesitamos de otros para actuar políticamente. La animalidad se manifiesta con mayor frecuencia en el ámbito doméstico, pero su relevancia política es innegable: Nuestra animalidad es un recordatorio permanente de nuestras limitaciones y deficiencias, y de nuestra consecuente dependencia de otras personas para sobrevivir y para vivir plenamente.

La negación de esta dependencia propia de nuestra naturaleza humana lleva a la desmesura que constituye uno de los principales vicios destructores de la política - la tentación de pensar que todo es posible, el rasgo distintivo del tirano en la antigüedad clásica.

Por otra parte, Arendt no parece tomar en cuenta que los seres humanos somos capaces de humanizar la labor y más aún, que las actividades de la labor pueden ser humanizantes. A diferencia del resto de los animales, los seres humanos podemos cubrir las necesidades de nuestro cuerpo de una forma específicamente humana, que da espacio a la libertad y al desarrollo personal; a la técnica, al gusto, al arte, a la moda, etc.

El acto sexual es un ejemplo muy obvio de esta idea: un hombre y una mujer pueden simplemente intimar con el fin de calmar por un tiempo el impulso sexual; o pueden formar un matrimonio y unirse en un acto que, si bien sacia el impulso sexual, aspira a ser una manifestación de amor y compromiso, además de ser un acto abierto a la concepción de una nueva vida que trascienda la vida de los mismos padres de lugar a un hogar familiar.

Las actividades de la labor pueden ser humanizantes, a pesar de no ser placenteras en sí mismas, ni aptas para aparecer en el ámbito público. El ejemplo más claro es el cuidado de un niño pequeño, de un anciano o de un enfermo. Todas estas actividades abren la puerta al ejercicio de la libertad personal y a la transformación del mundo de un modo efectivo a partir de la incidencia directa y benéfica en la vida de otra persona.

53 Es notable que "lazos sanguíneos" o "lazos de sangre" es otro de los significados de ỏvó $\gamma \kappa \eta$. Es cierto que podemos degradar este vínculo original y reducirlo a una mera conexión biológica y no humana. Tal sería el caso de un donador de esperma y otros casos similares: que sólo son padres en un sentido biológico y ni siquiera animal, en tanto que evitan la relación sexual. 
Es a través de las labores de cuidado y mantenimiento como somos capaces de construir la necesaria intimidad humana. Intimidad que inicia, sin duda, en el cuidado del cuerpo, pero que eventualmente madura hasta mostrarse como esa irreductible singularidad humana, que hace a cada persona un misterio inagotable $^{54}$.

Las labores de cuidado y manutención del mundo son mucho más que un simple intento de contención de la animalidad y de atención a las necesidades animales ocultas a la luz pública ${ }^{55}$. Las labores domésticas son la primera escuela de ciudadanía:

Es en el hogar donde los niños aprenden de manera práctica la importancia del cuidado de los bienes comunes - aquellos que nos pertenecen a todos en la familia, pero a ninguno de manera exclusiva ${ }^{56}$. El cuidado de los bienes comunes del hogar enseñará a los miembros de la familia a cuidar también los bienes comunes públicos de la ciudad. Bienes que también nos pertenecen a todos los ciudadanos, pero a ninguno de manera exclusiva. Bienes públicos materiales como parques, escuelas, plazas, transportes públicos; pero también bienes públicos intangibles, como las instituciones públicas, las investiduras y las instituciones democráticas; e incluso el cuidado de bienes públicos nocionales e imprescindibles para cualquier sociedad, como las leyes, el lenguaje y el dinero.

En la cotidianeidad de la vida doméstica se aprende el uso genuinamente económico de los recursos escasos. En el hogar se aprende a no desperdiciar, a cuidar los objetos de uso y a reciclar, a través de experiencias tan sencillas como las de heredar la ropa de la hermana mayor.

En el hogar aprendemos que, ante desafíos y problemas comunes, lo más urgente es encontrar soluciones viables, antes que buscar y castigar a los culpables. Actitud central para enfrentar cualquier crisis política seria.

En el hogar asumimos responsabilidad por algo más que lo estrictamente individual a través de labores ordinarias como lavar los platos usados por todos, poner y recoger la mesa.

Es también en el ámbito doméstico donde aprendemos a valorar y cuidar a los más vulnerables — bebés, ancianos, enfermos. El cuidado de los vulnerables es una actitud indispensable para mantener a cualquier sociedad lejos de la barbarie y la violencia.

\footnotetext{
54 Véase, Alvira, R. (2000), pp. 21-38.

55 Véase, Hurtado, R. \& Galindo, F. (coords.) (2019).

56 Véase, Argandoña, A. (ed.) (2018).
} 
Arendt afirma que las actividades de la labor son repetitivas y rutinarias; y

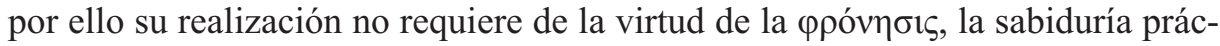
tica distintiva de la política ${ }^{57}$. Tal aseveración es inexacta. Quien como padre o madre ha llevado un hogar sabe que tanto la administración de los recursos siempre escasos, como la necesaria negociación permanente tanto con la pareja como con los hijos, demandan la sabiduría práctica, la virtud política por excelencia.

Es en el hogar donde a fuerza de fracasos, fricciones y nuevos comienzos aprendemos la belleza de lo imperfecto. La superioridad ontológica de la realidad posible con respecto al ideal inalcanzable. Superioridad ontológica que tiene consecuencias bien concretas y prácticas en cualquier ejercicio político: La búsqueda de lo posible y no de lo perfecto es una actitud característica de cualquier ejercicio sensato de la política. El amor a lo imperfecto, que se concreta en el amor a una familia, a "esta familia", es el remedio contra las utopías que suelen culminar en experimentos sociales abominables.

Arendt finaliza el capítulo dedicado a la labor con un diagnóstico impactante de una "sociedad de consumidores" por oposición a una comunidad política ${ }^{58}$. Tal sociedad coloca a la labor como la actividad humana primordial por encima del trabajo y la acción. En ella la acción es casi imposible y el trabajo (la fabricación) se hace al modo de la labor: los objetos fabricados dejan de abonar a través de su durabilidad y resistencia a la estabilidad del mundo; y más bien son desechados rápidamente para alimentar un ritmo de producción y consumo que evoca al ciclo de generación y corrupción característico de la naturaleza.

Una sociedad de "laborantes" es una sociedad de consumo cuyos miembros están atrapados por necesidades ficticias. Arendt acierta al denunciar el sinsentido y los excesos de una sociedad así. Pero no vincula esta crítica con la experiencia de las labores domésticas y familiares. Como hemos visto, la función de las labores domésticas es conservar el mundo y defenderlo contra la corrupción natural de todo lo viviente. La actitud fundamental (Grundeinstellung) de quienes laboran en un hogar se opone decididamente a la tendencia de excesos y al desperdicio de la sociedad de consumo.

\section{EL SECRETO DE ANDRÓMACA}

Paradójicamente, es a través del sentido de lo posible y el amor a lo imperfecto en la cotidianeidad familiar como una persona alcanza usualmente a enten-

57 Véase Arendt, H. (1981), p. 84.

58 Véase Arendt, H. (1981), Apartado 17. 
der el más noble de los ideales: la convicción de que algunas realidades, a pesar de su imperfección, merecen ser defendidas y preservadas, incluso a riesgo de perder la vida. Esta es la convicción heroica fundamental. $\mathrm{Y}$ así volvemos de nuevo a la enigmática frase de Héctor en la Ilíada que nos ha ocupado antes: " $\pi$ ó $\lambda \lambda$ "

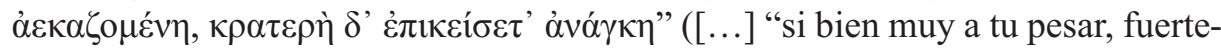
mente se te impondrá de todas formas la necesidad").

Hemos visto que Arendt, retomando una idea de Simone Weil, interpreta esta frase como una reafirmación de la condena que pesa sobre la humanidad y especialmente sobre la mujer relativa a las laboras en general y específicamente a las labores domésticas. En la interpretación de Arendt, la frase que Héctor dirige a su esposa Andrómaca, sería un recordatorio de que el peso de la labor es impuesto tanto por la naturaleza como por la convención de manera desproporcionada a las mujeres, puesto que las mujeres llevan a los niños en el vientre y además en muchos casos llevan también la casa.

En el mundo clásico griego, y también de acuerdo con la visión de Arendt, las mujeres eran excluidas por principio del ámbito público: no participaban en la Asamblea de ciudadanos, y no podían por ello ni votar ni ser votadas para ocupar cargos políticos y de gobierno; tampoco formaban parte del consejo de los $500 \mathrm{ni}$ de los tribunales. Condenadas a permanecer el ámbito doméstico las mujeres estaban también por consecuencia excluidas de alcanzar la fama y la gloria a través de acciones heroicas políticas o militarles. Y en una primera lectura en efecto parece que las palabras de Héctor confirman esta situación de exclusión y marginación. Empero, una perspectiva completamente diferente emerge cuando ponemos la frase en su contexto propio.

La escena se relata en el canto sexto en los versos que van de la línea 369 a la 502. Para ese momento de la épica la guerra se acerca a su terminación. Para todos, incluido Héctor mismo, es claro que Héctor no es rival para el poder de Aquiles - ninguno de los mortales lo es. Después de una breve conversación con su cuñada Helena, Héctor se apresura a su palacio a buscar a Andrómaca. Pero Andrómaca no está en sus habitaciones, sino en una de las torres del palacio, con el hijo de ambos en los brazos, llorando y lamentándose por el curso de la guerra y los augurios para Troya; pero al mismo tiempo escudriña la muralla que rodea la ciudad, tratando de encontrar los puntos más vulnerables.

Cuando por fin ambos se encuentran, Andrómaca abre la conversación recordando a Héctor lo desesperado de su situación: sus padres y sus siete hermanos murieron a manos de Aquiles; su madre fue secuestrada como parte del botín y puesta en libertad tras pagar abundante rescate, sólo para morir al poco tiempo. Andrómaca le recuerda a Héctor que él es lo único que queda de su familia, él es 
para ella "padre, madre y hermano". Andrómaca suplica a Héctor permanecer a salvo en la torre y lejos de la batalla; y no hacer del bebé de ambos un huérfano y de ella una viuda. De manera notable, Andrómaca concluye su letanía de lamentaciones y recuento de pérdidas con una petición concreta y eminentemente práctica: pide a Héctor mover a algunos de los guerreros a la parte más débil del muro para repeler el ataque de las fuerzas aqueas.

La respuesta inicial de Héctor a las súplicas de su esposa corre acorde con lo que esperaríamos de un héroe de la antigüedad clásica: Héctor menciona que sería vergonzoso para él retirarse de la batalla; que debe responder a la nobleza de su estirpe y de su sangre, y buscar la gloria para su padre y para él. Esta respuesta coincide también con la visión del héroe que presenta Arendt en La Condición Humana, tomando como ejemplo a Aquiles ${ }^{59}$.

Pero las siguientes palabras de Héctor implican un orden de prioridades radicalmente diferente del que esperaríamos: "Mas no me importa tanto el dolor de los troyanos en el futuro ni el de la propia Hécuba ni el del soberano Príamo ni el de mis hermanos -que, muchos y valerosos, puede que caigan en el polvo bajo los enemigos--, como el tuyo, cuando uno de los aqueos, de broncíneas túnicas, [455]

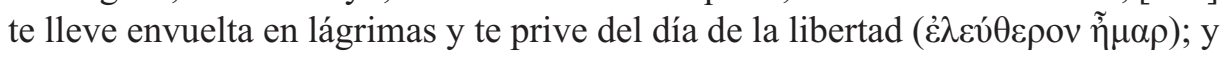
quizá en Argos tejas la tela por encargo de una extraña; y quizá vayas por agua a la fuente de Meseide o a la Hiperea; si bien muy a tu pesar, fuertemente se te impondrá de todas formas la necesidad" ${ }^{\circ 0}$.

Entonces Héctor intenta tomar en sus brazos a su hijo, pero el bebé siente miedo del poderoso casco del padre. Héctor y Andrómaca ríen al ver la reacción de su hijo. Después Héctor se quita el casco y toma al niño en sus brazos mientras dirige una plegaria a Zeus y a todos los dioses. Héctor pide que su hijo supere en grandeza y nobleza a su padre, y que alegre con sus hazañas el corazón de su madre Andrómaca.

59 Véase Arendt, H. (1981), p. 193.

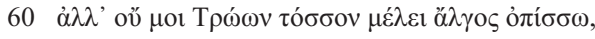

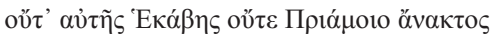

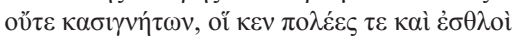

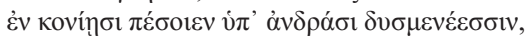

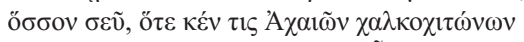

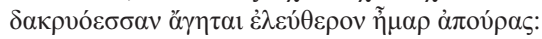

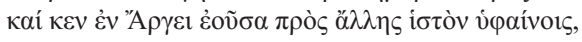

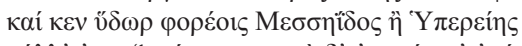

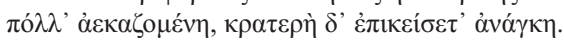
(Homero, Iliada, VI, 450-458; el texto aquí utilizado sigue estrechamente la traducción de Emilio Crespo Gümes (2000). Hemos modificado únicamente la puntuación; la frase clave que cierra el párrafo fue traducida por Fernando Galindo. 
Héctor devuelve entonces el niño al seno de su madre, quien entre lágrimas y riendo a la vez ( $\delta \alpha \kappa \rho v o ́ \varepsilon v ~ \gamma \varepsilon \lambda \alpha ́ \sigma \alpha \sigma \alpha$ ) lo recibe en su regazo. Finalmente Héctor

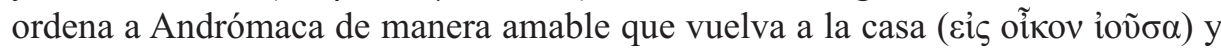

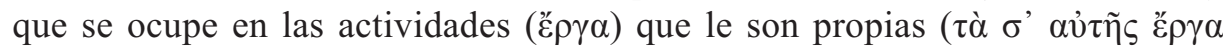

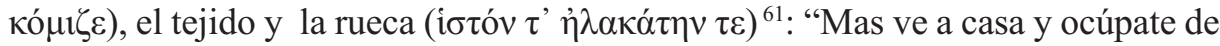
tus actividades, el telar y la rueca, y ordena a las sirvientas aplicarse a la faena. Del combate se cuidarán los hombres todos que en Ilio han nacido y yo, sobre todo" 62 .

Tras esta somera revisión, el significado de las palabras de Héctor es mucho más transparente: Héctor sabe que la suerte de Troya está echada, y no teme a la muerte; tampoco teme que sus compañeros guerreros o incluso su padre encuentren la muerte a manos de sus enemigos. Lo que sí perturba su corazón es que su mujer sea tomada como esclava, y que la necesidad se le imponga fuertemente

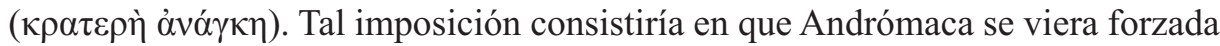
a realizar actividades propias de la labor, como el tejido y la rueca, y el llevado de agua para una familia ajena dirigida por alguna mujer noble en Argos.

En última instancia, el héroe troyano más grande no pelea por la gloria inmortal y memorable; tampoco es su primera preocupación defender a sus ciudadanos y ni siquiera a su patria. Lo que más agobia al héroe es garantizar la liber$\operatorname{tad}(\dot{\varepsilon} \lambda \varepsilon v \theta \varepsilon \rho i ́ \alpha)$ de su esposa. Héctor recuerda a Andrómaca que él es el único que puede protegerla de la esclavitud ( $\delta$ ov́ $\lambda \iota v$ ), y que prefiere morir antes que verla tomada como cautiva. Héctor se alegra pensando no en su futuro, como el victorioso campeón en la batalla contra Aquiles; sino en el futuro de su hijo. Y concluye pidiendo a Andrómaca que vuelva al hogar, a ocuparse de las labores del te-

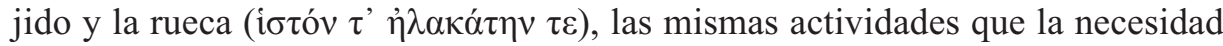
impondría sobre ella lejos de su patria.

La conmovedora escena sugiere que, al menos desde el punto de vista de Héctor, las hazañas heroicas tienen como último objeto la protección de la familia y del hogar. Y no parece que ni él ni Andrómaca consideren a las labores domésticas como necesariamente esclavizantes. La esclavitud se da cuando una mujer es obligada a realizar las labores propias de la intimidad doméstica por el bien de una casa ajena. Basta esta escena, aunque podrían mencionarse otras, para que la figura de Andrómeca aparezca distinta a la de un mero animal laborans.

61 Ibidem, VI, 490-491.

62 Ibidem. VI, 490-493. 


\section{CODA: REALIDADES FAMILIARES}

Cualquiera que hable de labores domésticas, o de la familia como una escuela de ciudadanía en el presente, debe enfrentar una crítica que no por repetitiva se ha vuelto menos común: Se nos reclama que hablamos de una familia "ideal", que permite el cuidado y florecimiento de sus miembros. Por el contrario, las familias "reales" son lugares de opresión y de violencia — la familia "es un infierno".

Esta crítica nos parece por una parte obvia y por otra parte mal direccionada. Nadie niega la existencia de dinámicas familiares destructivas. Al hablar de la importancia del hogar para la ciudad nuestra intención es recordar la relevancia y el papel insustituible de la familia como una de las instituciones básicas de nuestra sociedad en la construcción de la paz.

Cualquier persona dedicada a la prevención del delito, como es el caso de uno de los autores, sabe de primera mano que la prevención más efectiva inicia en el ámbito doméstico, en el seno de la familia. Y sabe también que la violencia familiar es la incidencia delictiva más común en el mundo ${ }^{63}$.

Es un error descalificar la función de cualquier institución básica de la sociedad a partir de las deficiencias de esta institución. Platón en su diálogo de madurez Leyes señala a través del personaje del ateniense este error:

El diálogo inicia con una discusión entre un ateniense (que jamás es nombrado y que se encuentra fuera de su región), un cretense llamado Clinias y un espartano llamado Megilos. La discusión gira en torno a una cuestión aparentemente trivial e idiosincrática, a saber, si los festivales atenienses que permiten el alcohol y dan lugar a borracheras, son en términos generales benéficos o perjudiciales para la ciudad.

Platón echa mano de una estrategia común en sus diálogos que consiste en iniciar con ejemplos sencillos y fáciles de entender para explicar realidades complejas. Menciona así, que quien juzgara y censurara a un rebaño de cabras como dañinas, por haber observado el daño que tal rebaño puede causar en los sembradíos cuando carecen de guía y mando o cuando son guiadas por un mal mando

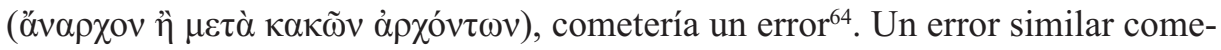

63 Además de su trabajo como docente, Fernando Galindo es desde febrero de 2019 director de Prevención Comunitaria (prevención del delito) en la Dirección General de Seguridad Pública del H. Ayuntamiento de Toluca, en México.

64 Cf. Leyes. 639a. 
tería quien censurara como dañinas a una reunión festiva o a una comunidad que,

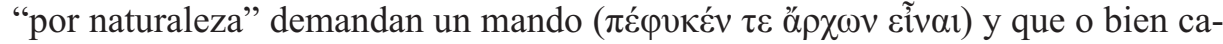

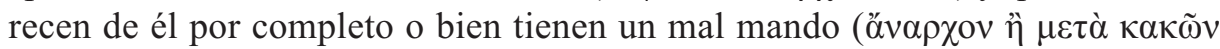
$\left.\dot{\alpha} \rho \chi \delta^{\prime} v \tau \omega v\right)^{65}$.

Tal persona no podría juzgar adecuadamente si nunca ha visto una celebración o una comunidad bien conducida, y tampoco nunca ha formado parte ni de tal tipo de reuniones ni del tal tipo de comunidades ${ }^{66}$.

Por último, el ateniense concluye, que por una parte procedería de manera adecuada, quien habiendo conocido cómo pueden llevarse a cabo tales celebraciones de manera correcta en las ciudades, encontrara de todas formas algo que criticar en tales asuntos ${ }^{67}, \mathrm{y}$ añade que: "por otra parte si alguien viendo a una de estas instituciones en su peor estado posible la criticara como despreciable $(\lambda \circ 1 \delta o \rho \varepsilon \tilde{i}) ;$ quedaría claro de entrada que tal persona ignora que aquello que ha devenido tal institución no es correcto; y además ignora que todo esto [la institución, celebración o comunidad] conducido de esta manera parece malo, cuando se realiza separado de un guía y un mando prudente ( $\delta \varepsilon \sigma \pi$ ó vท́ ( viera, o una armada de carros de guerra, o una tropa de infantería, o cualquier otra cosa que este bajo el mando de este timonel?"69.

Tal advertencia es igualmente relevante para las instituciones del presente: Sabemos que hay elementos de policía corruptos, y también médicos corruptos; y que la corrupción en las corporaciones policiales, como en cualquier otra institu-

65 Cf. Leyes, 639c. En todo el fragmento aquí referido que va de 639a a 641a es preponderante el uso de la ala-

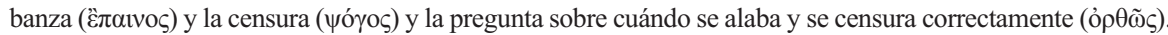
Ambas palabras no tienen una correspondencia adecuada en el uso común del español, por eso aclaramos

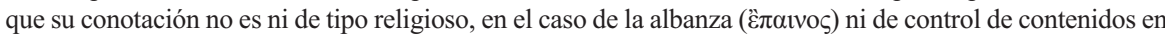
el caso de la censura ( $\psi o ́ \gamma o \varsigma)$, que se refiere más bien a reprobar un acto, institución, o costumbre por considerarla mala o vergonzosa o ambas. Para una explicación detallada del uso y las implicaciones de ambas palabras, así como de la red conceptual en la que se ubican nos permitimos referir a Galindo, F. (2013), que, si bien estudia específicamente el uso artistótelico de estos términos valorativos, lo hace desde una perspectiva de armonía y no de conflicto con la postura platónica.

66 Cf. Leyes, 639c-d.

67 Cf. 639e-640a.

68 Platón juega con el significado del adjetivo ví $\varphi \omega$, que significa "sobrio" por oposición a "borracho", pero también "sensato" o "prudente" en sentido figurado.

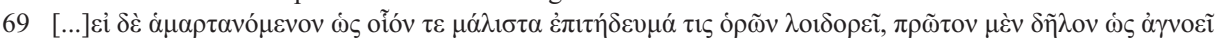

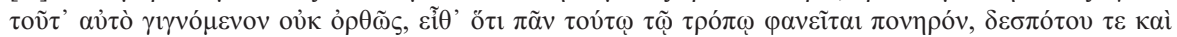

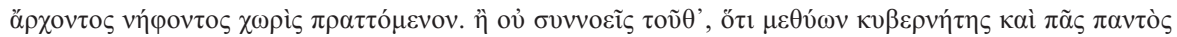

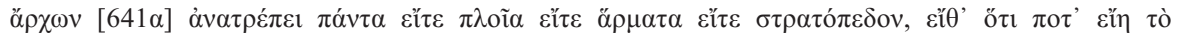

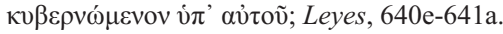


ción inicia por los mandos. Sin embargo, nadie propondría seriamente acabar con la policía o con los hospitales, ni nadie vería un problema o una aseveración controvertida en defender su función social insustituible. ¿Por qué sí sucede esto con la familia?

La reticencia a aceptar el papel de la institución de la familia en la sociedad contemporánea no responde a una realidad o problemática concreta. Como muestra la literatura del mundo greco-latino clásico, o la biblia, o cualquier texto fundacional, siempre han existido conflictos familiares.

Nos parece un hecho que la gran mayoría de los seres humanos nacen y mueren en familia. Y que es deseable que así sea. El amor fraternal, el amor paternoy materno-filial, y el amor de pareja siguen siendo formas del amor fundamentales en cualquier sociedad. No creemos que sea necesario presentar estadísticas para aceptar la verosimilitud de esta aseveración. Basta mirar cualquier obituario o asistir a cualquier rito funerario en el mundo: generalmente los deudos -los familiares- ocupan un papel prominente, y son los primeros a quienes se les ofrecen condolencias. La mayoría de los seres humanos hemos pasado este reciente confinamiento mundial en familia.

Basta también corroborar que las celebraciones más importantes de diversos países o de diversos ritos religiosos se pasan generalmente - muy generalmente en familia: pensemos en la celebración de la Navidad, o el día de acción de gracias en los Estados Unidos de América, o el año nuevo en China.

Tenemos la impresión de que la reticencia a aceptar el papel fundamental de la familia lamentablemente no responde a una inquietud científica o metodológica, aunque pretenda presentarse como tal exigiendo "estadísticas", "artículos indexados" o "pruebas históricas". Pensamos más bien que esta reticencia es consecuencia de un compromiso ideológico que se decanta, de nuevo, generalmente (no siempre ni en todos los casos) al menos en dos sentidos:

En un primer sentido el rechazo a la familia no es un rechazo a la familia como tal; se trata más bien de un rechazo al padre, al papel del varón en la familia. Ciertas corrientes de pensamiento y ciertos activistas sociales parecen empeñados en convencernos de que una familia no pierde nada cuando se da la ausencia del padre. Y para mostrarlo presentan ejemplos de padres (o padrastros) abusivos, violentos, alcohólicos, etc.

El orden del argumento es el mismo que en la crítica a la institución de la familia: Dado que hay padres abusivos, dañinos e incluso asesinos, es preciso prescindir o, mejor aún, abolir la paternidad. También en este caso el argumento es falso. La condición de orfandad, de padre, de madre, o de ambos no es nunca una 
condición deseable, ni que deba buscarse o promoverse. Perder a un buen padre es siempre, a cualquier edad, una pérdida dolorosa e irreparable. Hay quien llega a lamentar incluso haber perdido a un mal padre, precisamente porque la muerte le quita por completo la oportunidad, si bien lejana, de sanar esa relación tan fundamental y original. Del hecho de que nadie quiera tener un mal padre, hay quien concluye que es preferible que nadie tenga padre.

En un segundo sentido el rechazo a la familia es un rechazo a la Iglesia católica y a la tradición de pensamiento católico. Curiosamente hay quien llega a sugerir que la apuesta por la familia no puede ser una propuesta sensata y de sentido común, sino que es simplemente una posición "ideológica”. Y sin embargo resulta muy difícil encontrar cualquier sociedad en el presente o en la historia en que la relación paterno- y materno-filial, la relación fraternal o la relación matrimonial no sea especialmente importante: Un cónyuge no es lo mismo que un amigo; un hermano no es lo mismo que un colega; un padre o una madre no son lo mismo que un tutor o un jefe.

La centralidad de la familia es una realidad obvia en el mundo clásico grecolatino: No existen lazos más importantes que los lazos de sangre. El episodio de Héctor, Andrómaca y el Hectórida que hemos mencionado es solo un ejemplo. Pero los casos que pueden mencionarse son incontables: la relación de Aquiles con Peleo y con Tetis; la relación de Héctor, Paris y Príamo; la familia de Ulises, Penélope y Telémaco; la relación de Zeus con su esposa Hera y con sus hijas Atenea y Afrodita: ¡toda la teogonía helénica es una teogonía familiar! Y en su desarrollo no tuvo ninguna incidencia la Iglesia católica (espero que no nos pidan una demostración de esto). Y claro que abundan los casos de familias conflictivas y de relaciones complejas. La estirpe de Layo y de Yocasta es un ejemplo; o el caso de Medea y Jasón. Pero incluso en la estirpe de Layo y Yocasta existe el amor paterno-filial - Antígona ama genuinamente a su padre Edipo y lamenta profundamente su muerte y le duele su ausencia. Medea por su parte no se revela contra el matrimonio, sino contra la infidelidad matrimonial y la traición de Jasón, el "destructor de familias".

Afirmar que hablar de familia en el mundo clásico es una postura "ideológica católica" denota un gran desconocimiento del mundo clásico. Dado este rechazo a todo lo que parezca católico, nos vemos forzados a dejar de lado cualquier referencia a autores abiertamente católicos, para que se tome con seriedad nuestro argumento sobre la interpretación de las labores domésticas en Arendt a partir de esa cita clave, de la última y entrañable conversación entre Héctor, un padre y un héroe, y su esposa Andrómaca, madre y heroína. 
Por último, somos conscientes de que presentamos una visión "embellecida" de la familia y del hogar como escuela de la ciudadanía: el hogar como todo lo que puede ser; la escuela de la intimidad, del cuidado y de la donación; la escuela más importante de ciudadanía. Pero en esta presentación seguimos el mismo espíritu e incluso el método de Hannah Arendt: la polis, la Atenas de la que habla Arendt es también una versión embellecida de la Atenas real del siglo de oro. Una Atenas plagada de corruptelas, de traiciones e intrigas políticas.

Desafortunadamente una carencia extendida entre algunos estudiosos o entusiastas del pensamiento de Hannah Arendt es su poco conocimiento del mundo clásico. Algunos solo saben de las poleis griegas y la civis romana aquello que han leído en Arendt. Basta echar un vistazo no ya a autores contemporáneos como Josiah Ober, Kurt A. Raaflaub o Mogens Herman Hansen - sino simplemente a Herodoto o Tucídides para concluir que la Atenas que ensalza Arendt nunca existió como realidad histórica ${ }^{70}$.

La misma Arendt nos da la clave para entender su método en sus anotaciones sobre Homero: Como hizo antes Homero con la guerra de Troya, ella en su peculiar lectura de la polis clásica lleva a cabo un "embellecimiento" o "adornamiento" de una realidad histórica ${ }^{71}$. ¿Por qué podría Arendt "embellecer" la polis y no debiéramos nosotros embellecer el oĩkos, el hogar de la mano de héroes homéricos como Héctor y Andrómaca? Nos queda la inquietud de si es posible estudiar a Hannah Arendt seriamente sin al menos un mínimo de rudimentos de griego clásico, latín y conocimientos sobre el mundo clásico. Sospechamos que, si le preguntáramos a ella, su respuesta sería negativa.

Una de las consecuencias de este descuido, olvido o menosprecio del estudio histórico, es que tenemos a asumir una familiaridad con realidades que apenas conocemos $^{72}$. Y asociamos por ello la noción de familia con una batalla cultural contemporánea entre ilustrados individualistas y retrógradas conservadores. Pero el trabajo doméstico, las labores del hogar, la labor de parto, la maternidad, la fraternidad y por supuesto la paternidad, son realidades que anteceden a nuestras escaramuzas politíco-ideológicas contemporáneas, y que con seguridad las sobrevivirán. Esta es una de las enseñanzas del secreto de Andrómaca.

70 De M. Hansen se puede consultar su excelente introducción a la polis (2006); de Raaflaub, por ejemplo, Raaflaub, K.A. (2000) y de Ober, Ober, J. (1999).

71 "Embellecimiento" o "adornamiento" sería la traducción de "Ausschmückungen" en Arendt, H. (2003), p. 91. A su vez "Auschmückungen” es la traducción que Arendt hace de la expresión de Platón en Fedro:

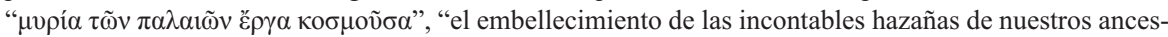
tros", con el fin de educar a las almas jóvenes. Cf. Fedro 245a. коб $\mu \varepsilon ́ \omega$ es un verbo derivado del sustantivo кó $\sigma \mu \varsigma$, que orginalmente significaba orden y joya y que es el origen de nuestra palabra cosmos.

72 Al respecto permítasenos referir a Galindo, F. (2019). 
Quizá por falta de cuidado histórico y filológico en ocasiones se insiste en estudiar a Arendt como una defensora de la emancipación femenina de cuño marxista y tradición feminista post-moderna; y no como lo que fue: una erudita, estudiosa y amante del mundo clásico, de Platón y Aristóteles especialmente, admiradora de Kant y discípula, para bien y para mal de Martin Heidegger; una filósofa y pensadora política de primer orden, que no cabe dentro de nuestras categorías combativas y militantes contemporáneas.

Tristemente la formación filosófica y filológica de Hannah Arendt nos es mucho más ajena, y mucho menos familiar de lo que creemos. Paralelamente, la existencia, persistencia e importancia de la familia-importancia que se nos manifiesta e impone una y otra vez, como en el reciente confinamiento de la pandemia-, nos es mucho más familiar y mucho más cercana, de lo que muchas veces estamos dispuestos a aceptar... a causa de compromisos ideológicos. 


\section{BIBLIOGRAFÍA}

Alvira, Rafael (2000), El lugar al que se vuelve, EUNSA, Pamplona.

Arendt, Hannah (1963), On Revolution, Penguin, Nueva York.

Arendt, Hannah (1981), Vita activa oder Vom tätigen Leben, Pieper, Múnich.

Arendt, Hannah (1996), "Fernsehgespräch mit Günter Gaus" (Entrevista televisiva con Günter Gaus) en Ursula Ludz (ed.), Ich will verstehen (Yo quiero entender), Pieper, Múnich.

Arendt, Hannah (1998), The Human Condition, University of Chicago Press, Chicago.

Arendt, Hannah (2002), Denktagebuch, Pieper, Munich.

Arendt, Hannah (2004), Was ist Politik?, Pieper, Munich. Editado por Ursula Ludz.

Argandoña, A. (ed.) (2018), The Home. Multidisciplinary Reflections, Elgar, Massachusetts.

Behe, Michael J. (2000), "Evidence for Design at the Foundation of Life", en Behe, Michael J. et.al. (eds.), Science and Evidence for Design in the Universe, Ignatius, San Francisco; pp. 113-122.

Eggers, Dave (2000), “A Heartbreaking Work of Staggering Genius”, Vintage, Nueva York.

Galindo, Fernando (2013), Lob und Tadel bei Aristóteles, Catálogo de la Universidad de Konstanz. Disponible en: http://nbn-resolving.de/urn:nbn:de:bsz:352240451

Galindo, Fernando (2019), “Cómo leer a los clásicos sin perder la razón?: a propósito de las reflexiones de Benjamin Constant" en Espino, J. ed. Recepción clásica y modernidad en siglo XIX, UNAM, México.

Hansen, Mogens. H. (2006), Polis, Oxford UP, Oxford.

Hill, Melvyn A. (ed.) (1979), Hannah Arendt: The Recovery of the Public World, St. Martin's Press, Nueva York.

Homer (2008), Ilias und Odyssee. Alemán - Griego. Trad. Johann Heinrich Voß. Zwetausendeins, Darmstadt.

Homer (1924), The Iliad with an English Translation by A.T. Murray, in two volumes. Cambridge, MA., Harvard University Press; London. 
Homero (2000), Iliada. Introducción general, traducción y notas de Emilio Crespo Güemes, Gredos, Madrid.

Hurtado, Rafael \& Galindo, Fernando (coords) (2019), A Stand for the Home. Reflexions on the Natural Family and Domestic Life, EUNSA, Pamplona.

Meyer, Stephen (2000), "Evidence for Design in Physics and Biology: From the Origin of the Universe to the Origin of Life" en Behe, Michael J. et.al. (eds.), Science and Evidence for Design in the Universe, Ignatius, San Francisco; pp. 53112.

Ober, Josiah (1998), Political Dissent in Democratic Athens, Princeton UP, Princeton.

Pape, Wilhelm (1914), Handwörterbuch der griechischen Sprache. Griechisch-deutsches Handwörterbuch, Two Volumes, Edited by Max Sengebuch, 3. Edition, Vieweg \& Sohn, Braunschweig.

Pitkin, Hanna (1995), "Conformism, Housekeeping, and the Attack of the Blob: the Origins of Hannah Arendt's concept of the Social" en Honnig, Bonnie (ed.), Feminist Interpretations of Hannah Arendt, Penn State Press, Pensylvania; pp. 51-82.

Platon (2005), Werke. Tomo 5. Phaidros, Wissenschaftliche Buchgesellschaft, Darmstadt.

Platon (2005), Werke. Tomo 8/1. Nomoi I-VI, Wissenschaftliche Buchgesellschaft. Darmstadt.

Raaflaub, Kurt. A. (2000), "Poets, lawgivers, and the beginnings of political reflection in archaic Greece", en Greek and Roman Political Thought. Rowe, C. et. Schofield, M. (eds.), Cambridge UP, Cambridge.

Rousseau, Jean-Jacques (1780-1789), Du Contrat social, en Collection complète des oeuvres, Genève, vol. 1, 4, edición en línea: en www.rousseauonline.ch (version du 7 octobre 2012). 